\title{
Effect of Bacillus mesonae H20-5 on Fruit Yields and Quality in Protected Cultivation
}

*Corresponding author

Tel: +82-63-238-3055

Fax: $+82-63-238-3834$

E-mail: mksang@korea.kr ORCID

https://orcid.org/0000-0001-9032-7012

\author{
Sung-Je Yoo ${ }^{1,2}$, Jeong Woong Kim ${ }^{3}$, Sang Tae Kim ${ }^{1,4}$, Hang-Yeon Weon ${ }^{1}$, \\ Jaekyeong Song ${ }^{1}$, and Mee Kyung Sang ${ }^{1}{ }^{1 *}$ \\ 'Division of Agricultural Microbiology, National Institute of Agricultural Science, Rural Development \\ Administration, Wanju 55365, Korea \\ ${ }^{2}$ Department of Agriculture, Biotechnology and Natural Resources, Gyeongsang National University, \\ Jinju 52828, Korea \\ ${ }^{3}$ Central Research Institute, Kyung Nong Corporation, Gyeongju 38175, Korea \\ ${ }^{4}$ Department of Applied Bioscience, Dong-A University, Busan 49315, Korea
}

Received June 4, 2019

Revised June 11, 2019

Accepted June 12, 2019

\begin{abstract}
A variety of microorganisms in rhizosphere affect plant health by plant growth promotion, mitigation of abiotic stresses as well as protection from pathogen attacks. In our previous study, we selected a bacterium, Bacillus mesonae $\mathrm{H} 20-5$, for alleviation of salinity stress in tomato plants. In this study, we verified the effect of a liquid formulation of $B$. mesonae $\mathrm{H} 20-5$ (TP-H20-5) on fruit production and phytochemical accumulation including lycopene and polyphenol in cherry tomato and strawberry fruits in on-farm tests of protected cultivation under salinity stress. When vegetables including tomato, cherry tomato, strawberry, and cucumber were treated with TP-H20- 5 by irrigated systems, final marketable yields were increased by $21.4 \%$ (cherry tomato), $9.3 \%$ (ripen tomato), $120.6 \%$ (strawberry), and 14.5\% (cucumber) compared to untreated control. Moreover, treatment of TP$\mathrm{H} 20-5$ was showed increase of phytochemicals such as lycopene and total polyphenol compared to untreated control in cherry tomato and strawberry. Therefore, these results indicated that a formulant of $B$. mesonae $\mathrm{H}_{20} \mathrm{O}$ 5 can be used as a potential biofertilizer for increasing fruit production and quality.
\end{abstract}

Keywords: Fruit quality, plant growth promotion
Vegetables including tomato, strawberry, and cucumber are generally grown in protective houses in Korea, however, there are a few problems such as salinity by continuous cropping system. Salinity is one of destructive stresses that can cause limit of growth and productivity (Munns and Gilliham, 2015). For mitigating salinity stress, in our previous study, we selected Bacillus mesonae $\mathrm{H} 20-5$ which can induce tolerance to salinity stress in tomato plants (Yoo et al., 2018).

Vegetables and fruits including tomato, strawberry, and cucumber have become well known as important sources

Research in Plant Disease

pISSN 1598-2262, elSSN 2233-9191

www.online-rpd.org for daily intake with phytochemicals. These bioactive constituents of fruits help protect against human diseases by antioxidant activity such as free radical scavengers or antimicrobial activity. The most known phytochemicals from fruits are polyphenols including flavonols, flavanones and cinnamate derivatives; lycopene in red color of fruits, they have medicinal values for reducing cardiovascular and prostate cancer diseases as well as one of determinants for fruit quality including fruit colors and firmness (Martínez et al., 2012).

In this study, we evaluated effects of a liquid formulation of $B$. mesonae $\mathrm{H} 20-5$ on marketable production of cherry tomato, ripen tomato, strawberry and cucumber in protected cultivation under salinity stress as well as fruit contents of bioactive components including lycopene and total polyphenol in cherry tomato and strawberry fruits. 
Table 1. Yields of cherry tomato, ripen tomato, strawberry, and cucumber treated with a liquid formulation TP-H20-5, ZY (a positive control), and untreated control during a growing season in protected cultivation under salinity stress

\begin{tabular}{ccccc}
\hline \multirow{2}{*}{ Treatment } & \multicolumn{4}{c}{ Total yield $(\mathrm{kg})$, (increasing rate, \%) } \\
\cline { 2 - 5 } & Cherry tomato & Ripen tomato & Strawberry & Cucumber \\
\hline Control & $1695^{\mathrm{a}}$ & 6050 & 114.3 & 1522 \\
ZS & $1835.5(8.3)$ & $6030(-0.3)$ & $56.7(-50.4)$ & $1810(18.9)$ \\
TP-H20-5 & $2058.5(21.4)$ & $6610(9.3)$ & $252.2(120.6)$ & $1742(14.5)$ \\
\hline
\end{tabular}

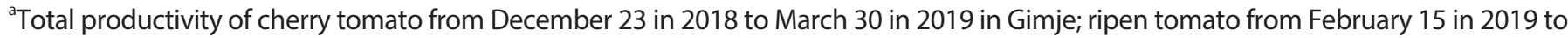
April 13 in 2019 in Gunsan; strawberry from December 20 in 2018 to February 28 in 2019 in Yangpyeong; cucumber from October 21 in 2018 to November 28 in 2018 in Gunsan.

On-farm tests for effect of a liquid formulation of $B$. mesonae $\mathrm{H} 20-5$ on fruit yield and quality in protected cultivation under salinity stress. In our previous study, salinity tolerant bacteria, B. mesonae H20-5, was selected (Yoo et al., 2018). In this study, we used a liquid formulation of $B$. mesonae $\mathrm{H} 20-5$ (TP-H20-5) produced by Kyung Nong Corporation for evaluation of fruit yield and quality in protected cultivation under salinity stress. For on-farm tests, four vegetables including cherry tomato, ripen tomato, strawberry, cucumber were tested. Three treatments including untreated control (water), ZY (@Zeroyeom) as a positive control, TP-H20-5 (final concentration $5 \times 10^{6} \mathrm{cell} / \mathrm{ml}$ ) produced by Kyung Nong Corporation were used by drip irrigation system during a growing season in protected cultivation. For cherry tomato test, seedlings (Solanum lycopersicum var. cerasiforme, 'Nonari') were transplanted into salinity soils (EC $4.7 \mathrm{dS} / \mathrm{m}$ ) located in province Gimje, Korea at September 29 in 2018; experimental field area was $660 \mathrm{~m}^{2} /$ treatment; each treatment was drip-irrigated at September 29 in 2018, October 10 and 26 in 2018. Marketable fruits of cherry tomato were harvested from December 23 in 2018 to March 30 in 2019. For ripen tomato, seedlings (Solanum lycopersicum L., 'SuperSunroad') were transplanted into salinity soils (EC $5.8 \mathrm{dS} / \mathrm{m}$ ) located in province Gunsan, Korea at September 15 in 2018; experimental field area was $660 \mathrm{~m}^{2} /$ treatment; each treatment was drip-irrigated at September 17, October 4 and 11 in 2018. Marketable fruits of ripen tomato were harvested from February 15 to April 13 in 2019. For strawberry, seedlings (Fragaria $\times$ ananassa, 'Seolhyang') were transplanted into salinity soils $(E C 3.0 \mathrm{dS} / \mathrm{m}$ ) located in province Yangpyeong, Korea at September 15 in 2018; experimental field area was $330 \mathrm{~m}^{2} /$ treatment; each treatment was drip-irrigated at September 20 and 30, October 9 in 2018. Marketable fruits of strawberry were harvested from December 20 in 2018 to February 28 in 2019. For cucumber, seedlings (Cucumis sativus L., 'Ipchunakhab') were transplanted into salinity soils (EC $5.8 \mathrm{dS} /$ m) in province Gunsan, Korea at September 15 in 2018; experimental field area was $660 \mathrm{~m}^{2} /$ treatment; each treatment was drip-irrigated at September 17, and October 4 in 2018. Marketable fruits of cucumber were harvested from October 21 in 2018 to November 28 in 2018. Total marketable production in the tested plants were accumulated.

During a growing season in on-farm tests, marketable productions of cherry tomato, ripen tomato, strawberry, and cucumber were evaluated (Table 1). Cherry tomato plants treated with TP-H20-5 produced totally $2058.5 \mathrm{~kg} / 660 \mathrm{~m}^{2}$ in a growing season, whereas untreated control and $\mathrm{ZY}$-treated plants did 1695 and $1835.5 \mathrm{~kg} / 660 \mathrm{~m}^{2}$, respectively. TP-H205 increased yield by $21.4 \%$ compared to untreated control. Ripened tomato plants treated with TP-H20-5 were harvested 9.3\% more; strawberry plants treated with TP-H2O-5 were dramatically increased $120.6 \%$ compared to untreated control plants. In case of cucumber plants, TP-H20-5 induced $14.5 \%$ higher productivity compared to untreated control. Treatment of $Z Y$ as a positive control increased productivity by $8.3 \%$ for cherry tomato, and $18.9 \%$ for cucumber, however, it decreased by $0.3 \%$ for ripen tomato and $50.4 \%$ for strawberry compared to untreated control (Table 1).

Fruit quality assessment of cherry tomato and strawberry plants influenced by a liquid formulation of $B$. mesonae H2O5. Marketable cherry tomatoes with four replications at February 11 in 2019, and strawberries with five replications at February 27 in 2019 were randomly sampled; each replication was consisted of five fruits. Sampled fruits of cherry tomato and strawberry were prepared by freeze drying method at $-40^{\circ} \mathrm{C}, 0.100 \mathrm{mbar}$ for 7 days; after maceration by 
a laboratory mill, powders passed through a sieve $(250 \mu \mathrm{m}$ opening micrometer, 60mesh), and then put into a scintillation vial and stored at $-80^{\circ} \mathrm{C}$ during a period of analysis (Hallmann, 2012). For polyphenol contents of cherry tomatoes and strawberries, extraction and measurement of fruit samples were followed by Vasco et al. (2008). Briefly, $0.2 \mathrm{~g}$ of freeze-dried samples were first extracted with $20 \mathrm{ml}$ of $50 \%$ methanol and then second extracted with $20 \mathrm{ml}$ of $70 \%$ acetone under continuous stirring for $1 \mathrm{hr}$. After extractions, supernatants were collected by centrifugation at 4,000 rpm for $15 \mathrm{~min}$. For measurement, $0.5 \mathrm{ml}$ of Folin-Ciocaltew reagent and $10 \mathrm{ml}$ of sodium carbonate solution was added, and then measured absorbance at $750 \mathrm{~nm}$ by a UV-vis spectrophotometry (Infinite M200 PRO, TECAN, Austria). Gallic acid was used as standard curves.

For lycopene contents of cherry tomatoes and strawberries, freeze-dried samples were extracted with hexane:ethanol:acetone (2:1:1, v/v) containing butylated hydroxytoluene, and the extract was determined using a at $505 \mathrm{~nm}$ by a UV-vis spectrophotometer (Kuti and Konuru, 2005)

For total soluble solid and titratable acidity of cherry tomatoes, fresh fruit samples were passed through a $1 \mathrm{~mm}$ metallic sieve for juice extraction. $1 \mathrm{ml}$ of the fruit juice was filtered using a syringe filter ( $0.45 \mu \mathrm{m}$ pore size), two drops of filtrate were carefully applied on the refractometer, and then total soluble solids were determined as percentage (brix range: 0 32\%) (Tigchelaar, 1986). For titratable acidity, $10 \mathrm{~g}$ of extracted juice was mixed with $50 \mathrm{ml}$ of deionized distilled water. The mixture was titrated by adding $0.1 \mathrm{~N} \mathrm{NaOH}$ until a $\mathrm{pH}$ 8.1, the added volume of $\mathrm{NaOH}$ was recorded, and then calculated by using titration formula for determination of titratable acidity (Anonymous, 1968).

Statistical analyses were performed using the Statistical Analysis System software (SAS Institute, Cary, NC). Pooled data from repeated experiments were used for statistical analysis after confirming the homogeneity of the variances by Levene's test. Analyses of variance were performed using the general linear model (GLM) procedure and differences between means were investigated using the least significant difference (LSD) test at $P<0.05$.

Bioactive components including polyphenol and lycopene, total soluble solid, and titratable acidity from fruits of cherry tomato plants treated with TP-H20-5, ZY, and untreated control were assessed (Fig. 1). There were signifi-
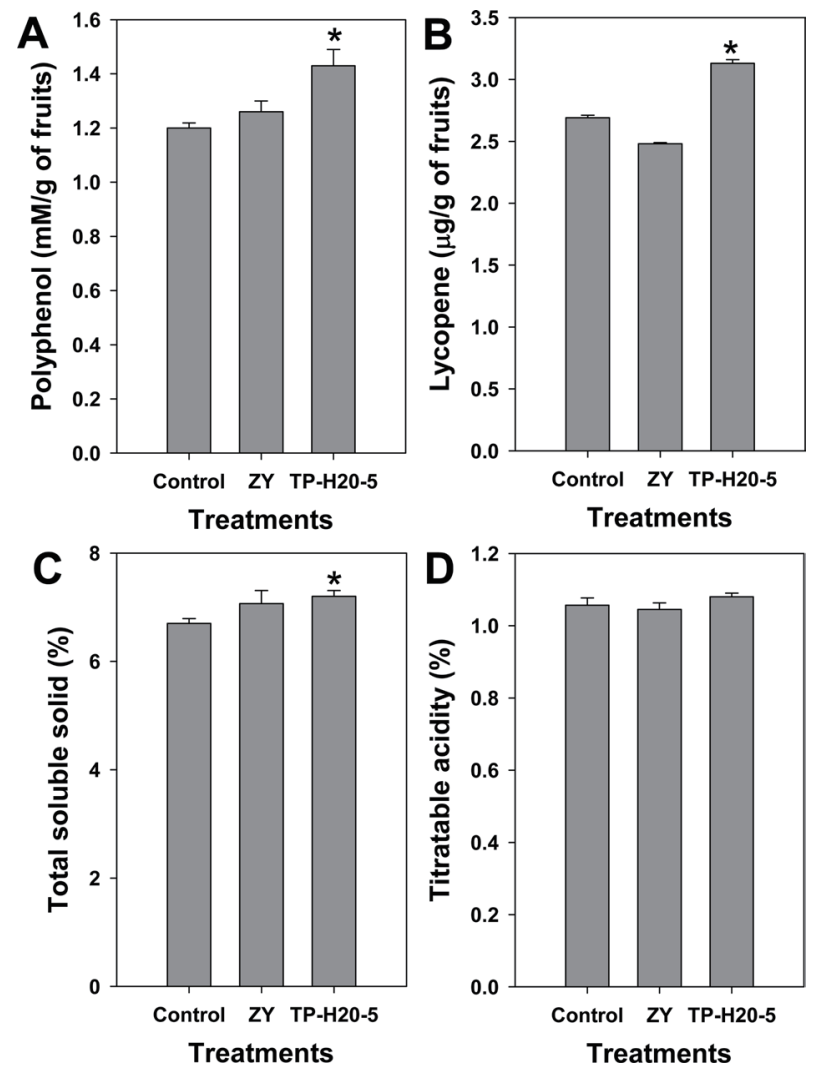

Fig. 1. Bioactive component and quality alterations on cherry tomato fruits by $B$. mesonae $\mathrm{H} 20-5$ (TP-H20-5) treatment. (A) Polyphenol, (B) lycopene contents, (C) total soluble solid (\%), and (D) titratable acidity from cherry tomato fruits in protected cultivation under salinity stress. Plants were treated with a liquid formulation B. mesonae $\mathrm{H} 20-5$ (TP-H20-5), $\mathrm{ZY}$ as a positive control, untreated control in on-farm located in Gimje, Korea. An asterisk on the bars indicates significant difference by LSD test at $P<0.05$.

cant effects of TP-H20-5 on bioactive component such as polyphenol and lycopene, total soluble solid, and titratable acidity compared to that of untreated control (Fig. 1). Bioactive components related to antioxidant such as polyphenol and lycopene significantly $(P<0.05)$ increased when TP-H2O5 was applied to cherry tomato plants (Fig. 1). Similar to polyphenol and lycopene, total soluble solid or titratable acidity related to consumer's tastes and flavor was also changed by treatments. Total soluble solid in cherry tomato fruits was affected by treatment TP-H20-5 but titratable acidity was not (Fig. 1).

When TP-H20-5, ZY, and untreated control were applied to strawberry plants, higher lycopene and polyphenol contents were achieved by TP-H20-5 (Fig. 2). Application of TPH20-5 increased the lycopene content by about ca. 97.77\%; polyphenol content by about ca. $13.83 \%$ as compared to 

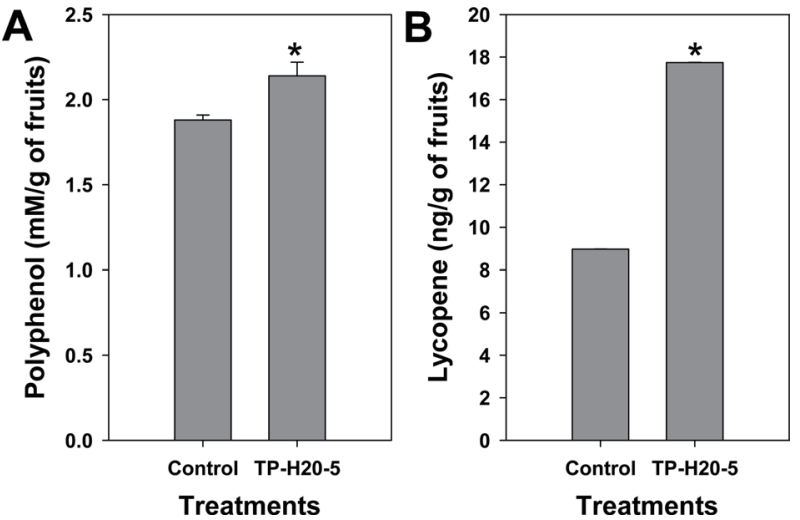

Fig. 2. Bioactive component alteration on strawberry fruits by $B$. mesonae H20-5 (TP-H20-5) treatment. (A) Polyphenol, and (B) lycopene contents from strawberry fruits in protected cultivation under salinity stress. Plants were treated with a liquid formulation $B$. mesonae $\mathrm{H} 20-5$ (TP-H20-5), $\mathrm{ZY}$ as a positive control, untreated control in on-farm located in Yangpyeong, Korea. However, fruits from ZY treatment were not tested. An asterisk on the bars indicates significant difference by LSD test at $P<0.05$.

untreated control (Fig. 2).

In this study, significant increases in marketable fruit were observed when TP-H20-5 was applied into vegetables including cherry tomato, ripen tomato, strawberry, and cucumber plants. Enhanced marketable yield by bacterial treatment had been reported. Mena-Violante and Olalde-Portugal (2007) observed tomato yield increasing by inoculation of B. subtilis; Bernabeu et al. (2015) showed that Burkholderia tropica could significantly colonized in the roots, and it led to an increase of tomato production in two different growing seasons. In addition to plant growth promotion by beneficial microorganisms under general growing conditions, other roles of bacterial strains in induced systemic tolerance (IST) against abiotic stresses are currently being studied (Singh et al., 2018). Especially, salinity is one of the most severe abiotic stresses during last few decades, it causes reduction in productivity and imbalance in development of plants (Cicek and Cakirlar, 2002). Origin bacteria $B$. mesonae $\mathrm{H} 20-5$ of TP-H20-5 was selected by mitigative effect of salinity and plant growth-promoting characters including phosphorus solubilization, (ACC) deaminase and phytohormone-like auxin production in our previous study (Yoo et al., 2018); in this study, its final effects in protective houses under natural salinity condition could be shown as increasing marketable productivity. Moreover, phosphorus solubilization activity of $B$. mesonae $\mathrm{H} 20-5$ from TP-H2O5 could help promote fruit yield by increasing a number of blossoms of tested plants during early stages of growth and fruiting (Sainju et al., 2003). As well as increased fruit yield, this study demonstrated that application of TP-H20-5 could play a role in accumulation of phytochemical contents in cherry tomato and strawberry. The lycopene and polyphenol contents of cherry tomato and strawberry in fruits were increased by application of TP-H20-5, which was similar results to Nzanza et al. (2012). It has been reported that these contents in fruits could be affected by environmental condition, ripening stage, and nutrient status; TP-H20-5 could induce tolerance to salinity and mitigate stress in plants; it could affect plant's lycopene and polyphenol contents. Moreover, the market quality of cherry tomato and strawberry fruit is affected by lycopene which is a major determinant of fruit color; therefore, TP-H2O5 could be an effective applicant to enhance fruit quality as well as quantitative yield.

Taken together, application of TP-H20-5 is required to increase fruit yield and quality including lycopene, polyphenol, and total soluble solid in protective cultivation under salinity by continuous cropping. Our findings of this study suggest that application of TP-H20-5 can be utilized as a potential biofertilizer for improving yield and fruit quality.

\section{Summary}

In this study, we verified the effect of a liquid formulation of B. mesonae H2O-5 (TP-H20-5) on fruit production and quality including phytochemicals in cherry tomato and strawberry fruits in on-farm tests of protected cultivation under salinity stress. When vegetables including tomato, cherry tomato, strawberry, and cucumber were treated with TP-H20-5 by irrigated systems, final marketable yields were increased by $21.4 \%$ (cherry tomato), $9.3 \%$ (ripen tomato), $120.6 \%$ (strawberry), and $14.5 \%$ (cucumber), and phytochemical components such as lycopene and total polyphenol compared to untreated control in cherry tomato and strawberry. These results implied that a formulation of $B$. mesonae $\mathrm{H} 20-5$ can be used as a potential biofertilizer for improving yield and fruit quality.

\section{Conflicts of Interest}

No potential conflict of interest relevant to this article was reported. 


\section{Acknowledgements}

This research was supported by a research grant (Project No. PJ011850) from Rural Development Administration, Republic of Korea.

\section{References}

Anonymous. 1968. Laboratory manual for food canners and processors. 3rd ed. National Canners Association, Westport, CT, USA. 444 pp.

Bernabeu, P. R., Pistorio, M., Torres-Tejerizo, G., Estrada-de los Santos, P., Galar, M. L., Boiardi, J. L. et al. 2015. Colonization and plant growth-promotion of tomato by Burkholderia tropica. Sci. Hortic. 191: 113-120.

Cicek, N. and Cakirlar, H. 2002. The effect of salinity on some physiological parameters in two maize cultivars. Bulg. J. Plant Physiol. 28: 66-74.

Hallmann, E. 2012. The influence of organic and conventional cultivation systems on the nutritional value and content of bioactive compounds in selected tomato types. J. Sci. Food Agric. 92: 2840-2848.

Kuti, J. O. and Konuru, H. B. 2005. Effects of genotype and cultivation environment on lycopene content in red-ripe tomatoes. J. Sci. Food Agric. 85: 2021-2026.

Martínez, R., Torres, P., Meneses, M. A., Figueroa, J. G., Pérez-Álvarez, J. A. and Viuda-Martos, M. 2012. Chemical, technological and in vitro antioxidant properties of mango, guava, pineapple and passion fruit dietary fibre concentrate. Food Chem. 135: 15201526.

Mena-Violante, H. G. and Olalde-Portugal, V. 2007. Alteration of tomato fruit quality by root inoculation with plant growthpromoting rhizobacteria (PGPR): Bacillus subtilis BEB-13bs. Sci. Hortic. 113: 103-106.

Munns, R. and Gilliham, M. 2015. Salinity tolerance of crops - what is the cost? New Phytol. 208: 668-673.

Nzanza, B., Marais, D. and Soundy, P. 2012. Yield and nutrient content of tomato (Solanum lycopersicum L.) as influenced by Trichoderma harzianum and Glomus mosseae inoculation. Sci. Hortic. 144: 55-59.

Sainju, U. M., Dris, R. and Singh, B. 2003. Mineral nutrition of tomato. J. Food Agric. Environ. 1: 176-183.

Singh, V. K., Singh, A. K., Singh, P. P. and Kumar, A. 2018. Interaction of plant growth promoting bacteria with tomato under abiotic stress: A review. Agric. Ecosyst. Environ. 267: 129-140.

Tigchelaar, E. C. 1986. Tomato breeding. In: Breeding vegetables crops, ed. by M. J. Bassett, pp.135-171. AVI Publishing Company, Westport, USA.

Vasco, C., Ruales, J. and Kamal-Eldin, A. 2008. Total phenolic compounds and antioxidant capacities of major fruits from Ecuador. Food Chem. 111:816-823.

Yoo, S.-J., Shin, D. J., Weon, H.-Y., Song, J. and Sang, M. K. 2018. Selection of bacteria for enhancement of tolerance to salinity and temperature stresses in tomato plants. Korean J. Organic Agric. 26: 463-475 (in Korean). 